\title{
De pícaros y picaresca en el judaísmo castellano
}

\author{
Carlos Carrete ParRondo \\ Universidad de Salamanca \\ Yolanda MORENO KOCH \\ Universidad Complutense, Madrid
}

A la memoria de Antonio Peral Torres, a quien recordamos con especial cariño

A veces y por motivos muy justificados tenemos la plena seguridad, avalada por un soporte cultural -y sobre todo tradicional-, de aceptar que determinados conceptos léxicos muy enraizados en el secular sentimiento del pueblo castellano tienen un muy determinado y exacto significado. Como, por ejemplo, los términos pícaro y picaresca, tan familiares como tradicional y literariamente demostrables, aplicables a un tipo de persona o de actividad «no exenta de simpatía, que vive irregularmente, vagabundeando, engañando, estafando o robando y evitando con astucia caer en manos de la justicia», como precisa María Moliner referente a la novela española del Siglo de Oro ${ }^{1}$. Sin embargo, la Real Academia de la Lengua ${ }^{2}$ al definir la voz pícaro ofrece cuatro acepciones: «1) bajo, ruin, doloso, falto de honra y vergüenza; 2) astuto, taimado; 3) dañoso y malicioso en su línea; y 4) tipo de persona descarada, traviesa, bufona y de mal vivir, no exenta de cierta simpatía, protagonista de obras magistrales de la literatura picaresca española». La diferencia entre ambos diccionarios es sustan-

1 Diccionario de uso del español (Madrid 1980) vol. II pág. 730a.

${ }^{2}$ Diccionario de la Lengua Española (21 a ed., Madrid 1992) vol. II pág. 1593b. 
cial y por supuesto, aunque en este caso sea extraacadémico, aceptamos el de María Moliner. Conviene recordar que si el empleo del correcto castellano tuviera que limitarse al estrictamente establecido por nuestros tradicionales académicos de la Lengua Española sería, en no pocas ocasiones, limitado a pesar de los actuales esfuerzos para una necesaria innovación.

Las anteriores precisiones semánticas parecen necesarias como introducción a las siguientes notas que deseamos presentar acerca de la actitud picaresca que ofrecieron determinados pícaros judíos y judeoconversos en el antiguo reino de Castilla durante los últimos años del siglo XV y los albores de la siguiente centuria.

No conviene olvidar que el pícaro puede ejercer su picaresca no sólo entre extraños y foráneos, sino también con quienes en teoría viven en una sociedad en la que la actividad picaresca puede emplearse, en principio, como uso de recíproco recibo. Este es un detalle, sin duda importante, al que más adelante dedicaremos algunas líneas.

El tema de los clérigos judaizantes, conversos o cristianos viejos, ha sido un aspecto que tradicionalmente se ha venido manteniendo casi al margen de la historia social española. Por sus especiales características ha pasado casi de puntillas entre los historiadores de nuestro pasado heterodoxo. Y no representa más que una faceta, no tan anecdótica como pudiera suponerse, que conviene destacar, no sin antes advertir que en esta época concreta nos hallamos antes del Concilio de Trento, etapa ciertamente renovadora.

Nos limitaremos a determinados casos, no muy conocidos ni espectaculares, pero que pueden reflejar la situación del clero castellano en ciudades no socialmente problemáticas en su convivencia con sus respectivas comunidades judías. Las excepciones, bien conocidas, no son representativas de la vida sencilla que en estas páginas pretendemos reflejar.

Variados son, en efecto, los personajes que, inmersos en una situación socio-religiosa de características muy definidas, se presentan ante el estudioso de la actividad que desplegó el Tribunal del Santo Oficio de la Inquisición en el distrito de Cuenca-Sigüenza durante los primeros años de su actuación. Profundas huellas sociales, extremado celo religioso, herencia cultural no siempre 
definida, preludio del incipiente Renacimiento y no poca picaresca forman, entre otros elementos, el panorama y medio en que convivieron judíos y judeoconversos. La consulta a tan importantes fondos documentales -tenemos que reconocerlo una vez más- nos ha sido facilitada por el durante muchos años años director del Archivo Diocesano de Cuenca, reverendo don Dimas Pérez Ramírez ${ }^{3}$.

1.- El proceso contra Diego González de Madrid, cura de la iglesia de San Nicolás de la conquense villa de Huete ${ }^{4}$, facilita múltiples noticias sobre el judaísmo castellano, incluso más allá de los límites territoriales de la región manchega. Fue acusado de que

rogó e importunó a un fiel cristiano que se fuese con él donde no los conociesen y donde pudiesen predicar y andar entre judíos, diciendo este buen clérigo que diría que era judío, y en este hábito que les predicaría su ley en su lengua hebraica, y así sacaría dinero.

Y continúa la acusación fiscal diciendo:

Y así pareció por experiencia que para poner en obra su herético pensamiento obtuvo una carta de un judío, rabí y principal entre los judíos 5 , el cual se la dio escrita en hebraico, encomendándole a las aljamas porque predicaba bien la ley de Moisés. Y así, con esta carta anduvo de aljama en aljama predicando y demandando sedacá ['limosna'], y dándoselo los judíos por la buena intención y que a su ley y doctrina mostraba las cosas que decía y cerimonias y ritos judaicos que hacía, ayunando y comiendo y dejando de comer, sabatizando y guardando las otras sus pascuas y fiestas, negando los beneficios de la ley de gracia.

${ }^{3}$ Los ejemplos documentales que ahora presentamos han sido tomados de las siguientes investigaciones de C. CARRETE PARRONDO: «Los clérigos judaizantes de Huete», Anuario de Estudios Medievales 12 (1982) págs. 411-419; (con una valoración psicológica por M. ${ }^{\mathrm{a}}$ J. CASTAÑo GONZÁLEZ), Fontes Iudaeorum Regni Castellae [= FIRC], I: El Tribunal de la Inquisición en el Obispado de Soria (14861502) (Salamanca 1985); con C. FRAILE CONDE, FIRC, IV: Los judeoconversos de Almazán, 1501-1505: Origen familiar de los Lainez (Salamanca 1987); y con M. ${ }^{a}$ F. GARCía CASAR, FIRC, VII: El Tribunal de la Inquisición de Sigüenza, 14921505 (Salamanca 1997). Aquí modernizamos levemente la transcripción paleográfica de los documentos.

${ }^{4}$ Con importante comunidad judía y judeoconversa, según estudió hace muchos años uno de los firmantes de la presente aportación. Vid. CARRETE PARRONDO «Los clérigos».

${ }^{5}$ Más adelante se indica que se trata de rabí Abraham Seneor, juez mayor de las aljamas del reino de Castilla. 
Y por que viesen el favor que el dicho judío principal y rabí le dio en su carta, le hizo traducir a un judío, escribiendo ${ }^{6}$ este y leyendo el mismo clérigo hebraico. Y comía pan cenceño de los judíos en sus pascuas. Y aun por mejor saber y predicar esta ley procuró comprar un libro porque contenía tales y tantas cosas que el judío vendedor le rogó que si los judíos supiesen que lo había vendido que le apedrearían ${ }^{7}$.

El documento, que no tiene desperdicio, continúa:

Y con este poco amor a la ley cristiana hacía burla de los cristianos viejos y le pesaba mucho del mal de los nuevos. Y aún más: aconsejaba que no vistiesen ni tomasen camisa limpia los sábados en la noche, ni otro día de la semana, sino el viernes en la noche.

Aquí hay una evidente equivocación y hay que interpretarlo no como viernes por la noche, sino antes de anochecer para recibir el šabat. Prosigue tan interesante documento:

$\mathrm{Y}$ con estas tales cosas no tenía conciencia en tomarlo a nuestra santa fe católica, falseando los testamentos de los difuntos, porque si el agonizante mandaba decir treinta misas por su alma, él ponía por escrito tres. Y así, por este camino y usando de tales falsedades, confesó y manifestó, como avaro e idólatra, que en poco tiempo había obtenido mucha hacienda. Y por injuriar a nuestra santa fe católica echó una imagen de San Miguel en un lugar muy deshonesto.

El clérigo confiesa personalmente ante los inquisidores conquenses que, teniendo edad de unos quince años, falleció su padre y quedaron a su cargo su madre y cinco hermanas pobres, por lo que decidió

tomar compañía con un fraile, y fuímonos a predicar, y en muchos lugares había judíos y moros, y a todos pedíamos limosna y de ellos recibíamos mantenimiento, como de los cristianos.

Siendo ya cura de la iglesia de San Nicolás, de Huete,

tuve que salir otra vez a causa de un destierro que nos fue hecho a todos los clérigos de la ciudad y volví a juntarme con otro fraile y tornamos a demandar de la misma forma y recibí limosnas de moros, judíos y cristianos, y esto por dar mantenimiento a mi madre y hermanas.

\footnotetext{
${ }^{6}$ No acabamos de entender bien la necesidad de un traductor / escribano judío.
}

${ }^{7}$ No hay duda que se trata de un sidur o devocionario judío. 
Entre los testigos que presenta el fiscal, un clérigo afirmaba que el procesado dijo

que se fuesen ambos a dos a donde no los conosciesen que hubiese judíos, y que Diego González diría que era judío y que los predicaría en su ley en hebraico, y que así sacarían de cada aljama tres o cuatro mil mrs. y que se los repartirían entre ambos.

En esta ocasión, como en tantas otras aunque a algunos estudiosos les cueste aceptar su evidente veracidad, no faltó la directa colaboración de determinados judíos con los inquisidores no para aunar fuerzas contra los heterodoxos del cristianismo, sino para tratar de destrozar socialmente a sus antiguos correligionarios, judeoconversos judaizantes ${ }^{8}$.

Rabí Isaac Comineto declara que viviendo en Pastrana, en la provincia de Guadalajara ${ }^{9}$, llegó allí

un abad con una carta de don Abraham Seneor en hebraico para las aljamas de Castilla, que socorriesen al dicho abad porque predicaba y adquiría bien por los judíos, y decía en hebraico que era «doréš tob le- 'amó» ${ }^{10}$, que en romance quiere decir que predicaba bien el dicho clérigo para su pueblo de los judíos. Y en la carta el clérigo se llamaba maestre Macías o fray Macías. Y que después de seis o siete años que pasó lo susodicho, este testigo tuvo que ir a Huete a vivir allí, por físico, y vio al clérigo, y este testigo le reconoció, y se llamaba Diego González de Madrid. Y dijo a Yuçé de la Moneda, su criado: «A este abad conocí yo, que se llamaba maestre Macías».

El ya mencionado Yuçé de la Moneda manifiesta ante el tribunal de la Inquisición que, residiendo en Huete,

le rogara un día Diego González de Madrid que le trasladase una carta, y que este testigo fuera a casa de Diego González, el cual le mostró una carta en hebraico, firmada de don Abraham Seneor, en que en efecto se contenía cómo don Abraham Seneor, como superior de los judíos, rogaba a las aljamas de Castilla que

${ }^{8}$ Sobre este tema vid. M. ${ }^{a}$ F. GARCía CASAR, «Judíos castellanos colaboradores con el Tribunal de la Inquisición del distrito Cuenca-Sigüenza», en Proceedings of the Tenth World Congress of Jewish Studies, Division B, Vol. II: The History of the Jewish People (Jerusalem 1990) págs. 175-182.

${ }^{9}$ Con comunidad judía documentada; vid. F. CANTERA Burgos y C. CARRETE PARRONDO, Las juderías medievales en la provincia de Guadalajara (Madrid 1975) págs. 58-62.

${ }^{10}$ En hebreo 'buen predicador para su pueblo'. 
diesen limosna al clérigo, el cual en la carta se llamaba fray Macías, y que en la carta decía en hebraico que él predicaba bien al pueblo de los judíos y que hablaba bien por su generación. Y que este testigo escribió y tradujo la carta en hebraico.

Otro judío, Abraham Cardenete, añade que el clérigo procesado se llegaba muchas veces a la tienda de este testigo, y hablando con él y con los que allí estaban, judíos, les decía algunos versos en hebraico, los cuales este testigo, como no sabe mucho el hebraico, no los entendía bien.

Y un último testigo judío, Osúa Azabán, escribano, declaró que este testigo iba a escribir a casa de Álvaro de Madrid, escribano, vecino de Huete, y estando allí escribiendo entró Diego González y dijo que le rogaba que le trajese Tehilim, que quiere decir Salterio, y que este testigo le respondió que le placía. Y como este testigo volvió otro día a casa de Álvaro de Madrid, el clérigo le tornó a decir que por qué no le traía el dicho Tehilim, y que este testigo le tornó a decir que sí traería, pero que nunca se lo dio.

Algunas de las anteriores testificaciones pueden servir de ejemplos para afirmar que en las comunidades judías establecidas en Castilla a finales del siglo XV la lengua hebrea estaba casi exclusivamente reservada al culto litúrgico, a determinadas manifestaciones literarias o a los estamentos culturales más altos de las aljamas; no trascendía, como algunos pretenden, al lenguaje coloquial del pueblo llano ${ }^{11}$.

El amplio resumen textual de tan interesante documento acaso pueda ofrecer parte de la panorámica situación de las comunidades judeo-castellanas en la segunda mitad del siglo XV, sobre la integración de los cristianos nuevos en una sociedad que sufría el rigor inquisitorial y, en defintiva, acerca de la formación, no siempre ortodoxa, de ciertos sectores del clero rural, poco antes de la profunda reforma religiosa que, patrocinada por el poder real, intentó sanear una situación en decadencia.

11 Vid. algunos ejemplos documentales en C. CARRETE PARRONDO, «El empleo de la lengua hebrea entre los judaizantes castellanos (siglos XV-XVI)», en W. Busse y M. Ch. VAROL-Bornes (dirs.), Sephardica: Hommage à Haïm Vidal Sephiha (Berna 1996) págs. 281-285. 
2.- A mediados del siglo $\mathrm{XV}$, con motivo de la muerte del rey Juan II, hubo duelos generalizados en todo el reino de Castilla, en los que, según costumbre, también participaron las comunidades judías.

Entre las acusaciones conservadas contra el soriano ${ }^{12}$ Juan Ramírez de Lucena figura una según la cual un judío se dirigía a la sinagoga y, al encontrarse con el protonotario apostólico, este le dijo: «Pasa tú, que más vales que yo, que vas a rezar el cadís ['oración fúnebre'] a la sinoga» ${ }^{13}$. Acaso en este ejemplo no convenga intentar rastrear ningún conato de antigua picaresca, sino -lo que es mucho más importante- de verdadero respeto hacia la religión ajena. La reconocida personalidad humana de Juan Ramírez de Lucena, así afirmada en otra documentación de la época, merece el mayor reconocimiento.

3.- A un clérigo soriano, García de Quintanar, se le acusa de rezar oraciones hebreas a modo judío, «sabadeando y meldando la cabeza y todo el cuerpo, alzando y bajando los brazos, frente a una pared». Y cuando le preguntaron por qué obraba así, «que parecen cosas de judíos y meldáis como judíos», respondió: «Hago oración porque estoy descomulgado y no puedo ir a la iglesia».

4.- Juan de la Isla, contador del duque de Medinaceli, dijo:

Pues que pese a Dios, ¿qué tenemos en este mundo sino morir, que con qué vivimos sino con mentiras? Que dicen: Va borracho el clérigo, que se come el pan y se bebe el vino, y dicen que se come y se bebe a su Dios, a la puta vieja de Santa María, que parió al otro y dicen que se quedó virgen.

En esta ocasión la hipotética picaresca -doble vida religiosa- se traduce en verdadera desilusión expresada en un recio y duro castellano.

${ }^{12}$ La ciudad de Soria albergó importante judería y numerosos judeoconversos; vid. F. CANTERA Burgos, «Juderías medievales en la provincia de Soria», en Homenaje a Fray Justo Pérez de Urbel, OSB (Silos 1976) vol. I págs. 445-482, y «Conversos y judaizantes en la provincia de Soria», Revista de Dialectología y Tradiciones Populares 32 (1976) págs. 87-102.

${ }^{13}$ Sobre la familia del protonotario vid. C. CARRETE PARRONDO, «Juan Ramírez de Lucena, judeoconverso del Renacimiento español», en A. MIRSKY, A. Grossman y Y. KaPlan (eds.), Exile and Diaspora: Studies in the History of the Jewish People Presented to Professor Haim Beinart (Jerusalem 1991) págs. 168-179. 
5.- Un escribano de Soria exclamó:

Mil abrazos he dado a mi mujer porque ya hemos casado a todas nuestras hijas; sólo falta una con hombre de mi generación y ralea, que si la llamaren judía ella le pueda decir a él judío.

Algún psicólogo podría ofrecer precisas conclusiones.

6.- El bachiller soriano, Rodrigo de Tardajos, es acusado de haber entrado en la sinagoga para escuchar un sermón pronunciado por un rabino y de haber hecho reverencia a la Torá. Respondió «que la reverencia que él hizo no fue a la Torá, sino a unos judíos honrados que allí estaban». Aquí el grafismo picaresco no puede ser más expresivo.

7.- A un vecino de Aranda de Duero ${ }^{14}$, en la provincia de Burgos, le acusan de que «hacía burla y escarnecía» a los que durante la Semana Santa lloraban y traían cubiertas sus cabezas. Decía: «De largas vías largas mentiras» y

ruin sea quien lágrimas echare. Pesar de Dios, que hace más de mil quinientos años que le mataron, y ¿que yo le llore ahora?; que juro a Dios que ni gota de lágrima.

Una vez más lo hondamente humano se confunde con una posible actitud picaresca.

8.- Un médico del mismo Aranda de Duero quería comprar una mula a otro judeoconverso, y al preguntar si la mula estaba sana, el dueño respondió: «Por Nuestra Señora que yo no conozco de ella más de lo que véis, que es buena mula». A lo que el comprador respondió:

No me juréis por Nuestra Señora, que no creo lo que me juréis por ella más que por aquella mula; mas júramelo por la ley de Moisés y os creeré.

9.- En un pueblo de Burgos, hablando un cristiano viejo con un fraile dominico judeoconverso sobre las penitencias, el primero dijo que hubo una batalla entre cristianos y que «a falta de clérigos se confesaban unos con otros, y que se podía hacer muy bien»,

${ }^{14}$ Con importante aljama judía; vid., por ejemplo, I. CADIÑanos BARDECI, «Judíos y moros en Aranda de Duero y sus contornos», Sefarad 50 (1990) págs. 4766 y $289-318$. 
a lo que el fraile respondió que «no aprovechaba más tal confesión que si se confesaran a la pared o a la cola de su mula».

10.- Maestre Diego, médico judeoconverso y vecino de otro pueblo burgalés, comentó un Jueves Santo:

Me maravillo de esta gente de recordar continuamente esta Pasión, porque cuando aquí matan a un hermano o pariente, en especial si le matan por justicia, no quieren que se lo recuerden, y esta gente hace lo contrario.

11.- Maestre Juan Tornero, vecino de Almazán, en la provincia de Soria, decía algunos sábados a un cristiano viejo: «Hijo, guarda la casa. Voy a oír un poco de un sermón que dicen en la sinagoga de un gran sermoneador» ${ }^{15}$. Habría que recordar que, de acuerdo con numerosa documentación de la época, era frecuente la presencia de judeoconversos en los sermones sinagogales. Y no solamente judeoconversos, sino también cristianos viejos, incluso clérigos.

12.- Un clérigo de Atienza ${ }^{16}$, en la provincia de Guadalajara, oficiando la misa dijo a otro sacerdote:

Parad mientes, que está aquí parte de un sacramento y mirad qué tan gruesas hostias hizo el sacristán, que por mi fe hay en cada una un yantar y en esta parte hay para un almuerzo.

13.- Un judeoconverso de la soriana villa de Medinaceli ${ }^{17}$ afirmaba que

alquilé un judío extranjero un día para cavar en una huerta mía y fuí a ver cómo cavaba, y me dijo que si yo le diese un sayo y un jubón y algunos dineros le diesen en la villa que se tornaría cristiano.

¿Se puede negar, ante este ejemplo, que el judío también participaba, y con toda normalidad, de la picaresca castellana?

14.- Ante tal panorama nada tiene de extraño que en el mismo año 1492 , meses antes de la expulsión, cuando un sacerdote leía públicamente en la iglesia un testamento, se escuchara la última

\footnotetext{
${ }^{15}$ Vid. C. Carrete Parrondo - C. Fraile Conde, FIRC IV, núm. 35 págs. 34-35.

${ }^{16}$ Sobre sus judíos y judeoconversos vid. CANTERA Burgos - CARrete PARRONDO Guadalajara págs. 11-19.

17 También contó con judíos y judeoconversos (vid. supra nota 12).
} 
voluntad de un judeoconverso: «Mando tanto a Mosé y tanto a Yudá y asímismo tanto a la sinoga».

15.- Más interés humano ofrece la acusación presentada en 1492 contra el segontino ${ }^{18}$ Rodrigo de Lucio; cuando enviudó en 1482 el cantero de la catedral exclamó: «iOh, pese a Dios, que no es posible que aquí viene cuerpo, sino tantos o algún diablo, según lo que pesa! (el ataúd)», porque, sigue explicando el documento

la noche antes que la enterrasen llevaron el cuerpo al honsario de los judíos, y que cuando salieron por la puerta de la ciudad dijo uno de los que iban con el dicho cuerpo: «¿A dónde vas?», y que él le respondió: «Acá curan, señores, los muertos». Y que entonces le dijo el susodicho: «No hemos de ir allá, sino al fonsario de los judíos».

16.- En el año de la expulsión general se acusaba a un vecino de Sigüenza «cómo estaba circuncidado, mas que había sido por una enfermedad que en su miembro le había nacido» y se añade que, aunque se lo vieron «cortar, a su padre se le había perdido el testimonio» del correspondiente médico. Aquí tampoco sirven paliativos: si lo leyéramos en una supuesta novela picaresca recientemente encontrada aceptaríamos el fácil planteamiento sin ninguna dificultad.

Ahora no nos interesan en absoluto cuáles fueron en su caso las decisiones jurídicas que adoptaron los inquisidores. Sólo indicar, una vez más, que los judeoconversos residentes en el antiguo reino de Castilla también se asimilaron a lo que los cristianos viejos entendían por picaresca. Las costumbres sociales entre ambos sectores de la población eran semejantes en muchos aspectos. En ocasiones se ha afirmado -lo hemos afirmado- que los pícaros existieron antes que la novela picaresca y que el judío castellano, a la par que judío, se sentía eminentemente castellano. Otra cosa muy diferente es que, desde que puede emplearse con corrección el término España se sintiera español. Pero ese es otro tema que tal vez convenga examinar en otra ocasión.

\footnotetext{
${ }^{18}$ Sobre los judíos y judeoconversos de Sigüenza vid. en principio CANTERA BURgOS - CARRETE PARRONDO Guadalajara págs. 62-90.
} 


\section{RESUMEN}

Se presenta una selección de dieciséis ejemplos documentales pertenecientes a los últimos años del siglo XV y primeros del XVI, conservados en los fondos inquisitoriales del Archivo Diocesano de Cuenca. En su contenido puede advertirse el empleo de la actitud picaresca entre judeoconversos del antiguo reino de Castilla.

\section{SUMMARY}

The present study includes excerpts from sixteen historical documents dating from the latter part of the fifteenth century to the beginning years of the sixteenth. Their provenance is the Inquisition Section in the city of Cuenca's Cathedral Archive. From their contents and tone, one detects roguish behavior between and among New Christians (judeoconversos) residing in the Kingdom of Castile. 